\title{
Globalização: em direção a um mundo só?
}

\author{
HENRIQUE RATTNER
}

$\mathrm{O}$ ACORDO ALCANÇADO na Rodada Uruguaia do GATT; a criação da OMC Organização Multilateral de Comércio; os avanços e os recuos na implantação do MERCOSUL; as repercussões e esperanças despertadas pelas reuniões da APEC e da NAFTA: tudo tende a fortalecer na opinião pública a impressão de que estaríamos no limiar de um período de bonança devido à integração - ainda que competitiva - da economia mundial. Essa tendência é aclamada não somente como inelutável e irreversível, mas também como vantajosa e necessária para todos os países e suas populações, indistintamente. Internacionalizar, abertura total, privatizar passam a ser consideradas respostas mágicas para resolver os problemas da fome, do desemprego, das favelas, da violência, enfim, ter-se-ia redescoberto a via-mestra do desenvolvimento.

Um balanço mais objetivo dos resultados da política de abertura adotada nolens volens pelos países periféricos e endividados revela os efeitos perversos dessa liberalização, que deixa suas seqüelas sob forma de cortes impiedosos de postos de trabalho, queda dos níveis salariais - também nos países industrializados e a perda generalizada dos benefícios conquistados na época do welfare state, que está definhando.

Em conseqüência, agravam-se os conflitos entre grupos de interesse que lutam por fatias decrescentes do produto social, multiplicados por choques entre grupos étnicos e religiosos longamente reprimidos, frustrados e desesperançados face à inoperância do sistema e das instituições.

Efetivamente, à medida que a competição pelos mercados se acirra, os ricos e poderosos tornam-se mais soberanos e os pobres, em número crescente, mais miseráveis.

Fator agravante desse processo de polarização e exclusão é constituído pela perda paulatina da capacidade do Estado de levantar recursos, via tributos e impostos, para atender às demandas cada vez mais urgentes, não somente das massas, mas também das classes médias angustiadas pelo desemprego, custo e baixa qualidade da educação, falta de segurança e deterioração generalizada da qualidade de vida. 
À mobilidade praticamente ilimitada do capital financeiro e industrial, os governos tentam em vão opor barreiras à penetração de bens e serviços, amplamente facilitada pela liberalização a favor do mercado global. Mas também os países desenvolvidos, com economias integradas, começam a perder investimentos e, portanto, empregos, que migram para regiões e países onde a mão-de-obra relativamente qualificada é mais barata, a legislação trabalhista é leniente e as restrições à poluição ambiental carecem do rigor da lei.

Afinal, quem comanda a economia?

Avolumam-se evidências de que, na economia global, cada vez mais é o mercado financeiro, ou seja, as grandes corporações e não os governos, que, em última análise, decide sobre os destinos do câmbio, da taxa de juros, dos preços das commodities, da poupança e dos investimentos. Sem dúvida, a liberalização e a globalização dos mercados são altamente vantajosas para o grande capital, cujos horizonte e estratégia transbordam as fronteiras estreitas do Estado nacional. Exportar mais, mesmo às custas do suprimento de alimentos básicos, para importar mais (especialmente, bens de luxo e de consumo conspícuo) e pagar os juros da dívida externa, para tranqüilizar os bancos credores e atrair novos investimentos estrangeiros (ainda que altamente especulativos) têm constituído receita prescrita para a retomada do desenvolvimento. Dificilmente encontrar-se-á uma referência às prioridades sociais na retórica dos arautos da globalização.

A crise mexicana, que estourou em fins de 1994, representa um caso emblemático não somente para o Brasil e a Argentina, mas também para outros países pressionados a seguirem as prescrições do Fundo Monetário Internacional. O corte drástico nos gastos do Estado para assegurar o equilíbrio orçamentário; a desregulação e a privatização de empresas estatais; a desvalorização cambial para aumentar as exportações, acompanhada de abertura do mercado para importações e, finalmente, a elevada taxa de juros para manter baixo o nível de inflação e, ao mesmo tempo, atrair capital estrangeiro, constituem o elenco de políticas impostas, contraditórias e violentamente anti-sociais em suas conseqüências. A estratégia baseada em reservas cambiais (voláteis e ilusórias) caiu por terra, deixando como seqüelas o maior endividamento do país e a elevação das taxas de juro que alimenta, ao mesmo tempo, a inflação e a recessão econômica.

O drama mexicano não deixou de proporcionar momentos hilariantes, quando da presteza com que os governantes brasileiros e outros latino-americanos se prontificaram a socorrer o povo mexicano.

Afinal, quem se beneficiou com os movimentos especulativos do mercado financeiro? A debacle mexicana evidenciou não somente o fracasso estrondoso da política de reajuste estrutural mas também a conivência e cooptação das elites e da tecnocracia nacionais pelo capital financeiro internacional, ainda que os custos 
sociais se tornem insuportáveis. A estabilidade(?) precária e efềmera alcançada pela moeda mexicana após as operações de socorro do BM e a penhora das receitas futuras da indústria petrolífera do país constituem mau presságio para a Argentina e o Brasil que descapitalizados e com o setor estatal enxugado e privatizado, terão de enfrentar os credores internacionais. Para socorrer o México, foram necessários US\$ 45-50 bilhões. Seria possível mobilizar outros tantos para a Argentina e o Brasil?

O governo argentino, para merecer a ajuda do FMI, foi obrigado a se submeter a condições draconianas, implicando aumento assustador de desemprego e da miséria. E, o Brasil, até quando poderá manter a liberalização de seu comércio exterior, baixando alíquotas e tarifas alfandegárias? Seriam todas essas medidas suficientes para inspirar confiança e atrair os capitais transnacionais manipulados por investidores privados e fundos em busca de lucros elevados, rápidos e seguros e, por isso, extremamente voláteis e móveis a ponto de nem os governos nacionais, nem as instituições financeiras internacionais serem capazes de sustar os lances especulativos e coordenar as políticas econômicas e financeiras?

A dura experiência dos últimos anos nos ensina que a política econômicofinanceira - em que pesem os relatórios otimistas de consultores nacionais e internacionais - não foi capaz de atrair e inspirar confiança aos investidores estrangeiros, apesar de serem seguidas as prescrições de reduzir as despesas governamentais, liberalizar o comércio, privatizar e desregular, e manter elevadas as taxas de juros. São essas mesmas taxas de juros que drenam os parcos recursos do país, enquanto os reajustes fiscais em si não são capazes de reduzir as pressões inflacionárias decorrentes da incerteza quanto ao futuro da sociedade em desenvolvimento.

Por outro lado, a dívida social acumulada reforça e dissemina um clima geral de insegurança e incerteza, tendendo a afugentar prospectivos investidores nacionais e estrangeiros. Como, então, reiniciar e consolidar o processo de desenvolvimento, face ao nervosismo do capital e às condições extremamente favoráveis a sua mobilidade, na era da globalização em que persistem barreiras e protecionismo?

Os pouquíssimos exemplos de uma industrialização tardia bem-sucedida, portanto, mais durável do que meros movimentos cíclicos ou conjunturais, apontam para um conjunto de fatores e aspectos das políticas econômica e social, fundamentais no processo de desenvolvimento.

A base do esforço foi repousar na poupança interna, estimulada por elevações sucessivas de renda da força de trabalho e no empenho permanente para reduzir as disparidades regionais, setoriais e sociais.

O desmoronamento do socialismo real ao Leste não deve significar a aceitação passiva das injustiças gritantes do regime de mercado. A tributação justa 
dos ganhos e de fortunas acumuladas e a penalização severa dos sonegadores, se, por um lado, podem assustar os donos do capital, por outro, despertarão a confiança dos mesmos nas regras do jogo estabelecidas pelo governo, apoiado por sentimentos de solidariedade e de cooperação indispensáveis para vencer os obstáculos ao desenvolvimento nacional.

A renda mínima garantida a todos os necessitados, combinada com um comportamento caracterizado pela austeridade, competência e dedicação das lideranças, em um clima de liberdade e respeito aos direitos humanos constituem os pilares de uma sociedade sustentável.

\section{O novo contexto}

No tópico anterior, apontei para os efeitos dramáticos da globalização, particularmente nas economias dos países periféricos. Comentários e observações críticas feitas por colegas, acusando-me alguns de pessimismo excessivo, outros cobrando alternativas, levam-me a voltar ao assunto, movido pelo interesse de alimentar a discussão sobre os futuros possíveis e desejáveis para a humanidade.

Embora conduzido pela economia, o processo de globalização transcende os fenômenos meramente econômicos e, para o entendimento de toda a sua extensão e profundidade, deve ser apreendido também em suas dimensões políticas, ecológicas e culturais. Ademais, buscando formular as premissas de alternativas de desenvolvimento numa perspectiva histórica, portanto, sem rejeitar a globalização, procura-se apontar para as opções abertas, dentro desse marco, à cooperação pacífica entre povos e Estados, à democratização e à universalização dos direitos humanos e à solidariedade internacional dos movimentos sociais.

Em retrospectiva histórica, a globalização iniciou-se no pós-guerra, com a expansão acelerada e ininterrupta da internacionalização da economia, configurada pelo crescimento do comércio e dos investimentos externos, a taxas bem mais altas do que o aumento da produção mundial (PMB - Produto Mundial Bruto). Essa tendência foi intensificada pela entrada em cena de instituições internacionais (GATT, FMI, BIRD, FAO etc.) que, por um lado, acentuaram a centralidade dos países-membros da OCDE e, por outro, lançaram um processo de acoplamento e integração seletiva de alguns países periféricos (os NICs - newly industrialized countries), incorporando-os aos planos de expansão, mediante uma nova divisão internacional de trabalho das empresas transnacionais. Os empréstimos e créditos fáceis e baratos em euro e petrodólares estão na origem dos milagres nos anos sessenta, que contemplaram os países em desenvolvimento com uma capacidade produtiva baseada em intensidade energética, matérias-primas e mão-de-obra baratas e processos altamente poluentes.

A década de oitenta confirmou o advento, a partir do Japão, de um novo paradigma de produção e de organização industrial, combinando a automação 
flexível com gestão e sistemas de comunicação informatizados. O complemento político para a universalização do novo paradigma foi proporcionado pela desregulação, privatização e desestatização, liberando os mercados não só para uma concorrência desenfreada das corporações transnacionais, mas também eliminando inúmeras pequenas e médias empresas. Entre as características mais marcantes da nova configuração político-econômica internacional, merece destaque, entre outras, a integração acelerada dos mercados financeiros nacionais e internacionais, ligados por redes de comunicação via satélite e apoiados por poderosos sistemas informatizados, que permitem a perfeita mobilidade do capital em suas operações num espaço-mercado global e a formação de consórcios e de joint-pentures entre corporações transnacionais, de bases territoriais-nacionais diferentes. Essas alianças e acordos interempresas visam não somente à redução dos custos de P\&D (pesquisa e desenvolvimento) de novos produtos e processos, mas também ao acesso a mercados regionalizados cujas barreiras à entrada de não-membros continuam proibitivas.

Finalmente, a complexidade e a velocidade de mudanças nas relações interconglomeradas e suas intervenções nos mercados financeiros, possibilitadas pela mobilidade intensa do capital, têm levado os governos dos principais países capitalistas (G-7) a procurarem instrumentos e mecanismos de coordenação das políticas econômico-financeiras, por sinal, de eficácia limitadíssima. Se acrescentarmos o desmoronamento do socialismo real na ex-União Soviética e os caminhos atabalhoados de sua transição ao capitalismo; a entrada da China, através das quatro modernizações, na economia mundial, abrindo um mercado potencial de um bilhão de consumidores; o colapso de sociedades que optaram pela terceira via (Argélia, ex-Iugoslávia); e o caos reinante em 50-60 países do quarto mundo, teríamos configurado, ainda que sumariamente, os desafios a serem enfrentamos na busca de alternativas, dentro do espírito de nosso futuro comum.

\section{O desafio político}

Caracterizamos a globalização como o resultado de um processo histórico, cujos fatores dinâmicos são a concentração-centralização de capital, o desenvolvimento dos meios de comunicação e o despertar da consciência sobre o destino comum da humanidade. Essa tendência manifesta-se, também, na difusão de padrões transnacionais de organização econômica e social, de consumo, de formas de lazer e de expressão cultural-artística, enfim, um estilo de vida decorrente das pressões competitivas do mercado, que aproximam culturas políticas e práticas administrativas e difundem e generalizam os mesmos problemas e conflitos ambientais.

Admitindo-se a irreversibilidade da globalização, com seus efeitos e impactos positivos e negativos em nível das comunidades e nações, simultaneamente integradores e desestruturadores, permanece a tarefa formidável de como conduzir 
e orientar esse processo sem cometer falácias e confundir as conseqüências da acumulação centralizadora de capital (crise social, desemprego, erosão e aniquilação de culturas e valores tradicionais) com as oportunidades efetivas de integração, aproximação e cooperação em nível mundial, proporcionadas pela globalização. A onda de democratização, ainda que débil, atravessa os continentes, desde os confins do sudeste asiático até a América Latina, passando também pela África, assinala que as populações não mais aceitam silenciosamente os regimes de opressão, exploração e corrupção ainda prevalecentes na maioria dos países. A busca de opções e alternativas, dentro do contexto e dos rumos da globalização, enfrenta o dilema de como superar a contradição fundamental inerente ao sistema social que acirra constantemente o espírito competitivo, enquanto condições objetivas exigem cada vez mais a cooperação em todos os níveis, como condição sine qua non para a emancipação de todos os povos, inclusive dos condenados da terra.

Afetando todas as esferas da vida - os padrões de trabalho e de educação; as formas de lazer e de expressão artística; e as tecnologias, os processos de organização e administração nas empresas e instituições públicas; a globalização coloca na ordem do dia a necessidade inadiável de mudanças sociais e de reestruturação da ordem mundial, face à inadequação e inoperância dos quatro princípios que sustentam as organizações das Nações Unidas. O princípio de não-intervenção nos assuntos internos dos países de menor expressão territorial e política tem sido freqüentemente ignorado pelas grandes potências, invalidando, concomitantemente, o da autodeterminação dos povos. Trajetória pior ainda teve o princípio de respeito aos direitos humanos, sacramentado pela Carta das Nações Unidas. Após 50 anos de sua existência, continuam as violações e a negação da liberdade por muitos governos, sobretudo nos países pobres e periféricos. A observância desse código e os hipotéticos efeitos do crescimento econômico iriam assegurar a gradual evolução das sociedades em direção a sistemas democráticos, uma previsão que também se mostrou totalmente irrealista. $\mathrm{O}$ que nos permitiria, então, encarar a globalização - apesar dos fracassos de seu meio século de existência - das Nações Unidas, como fator positivo no desenvolvimento da humanidade?

Em primeiro lugar, a globalização surge como a condição objetiva fundamental das transformações estruturais em direção a um mundo solidário, pacífico e de cooperação de todos os povos para superar os antagonismos e conflitos decorrentes da competição entre economias nacionais. Segundo, a degradação ambiental em conseqüência da externalização dos custos pelas empresas tem causado problemas de saneamento, de saúde e marginalização sócio-cultural, cuja superação exige não somente tecnologias apropriadas e recursos financeiros nacionais e internacionais, mas também a formação de uma consciência social e de um poder político global. Em terceiro lugar, tendo emergido como produto de processos materiais e espirituais, um retrocesso da globalização causaria danos econômicos e ecológicos, levaria à regressão a regimes políticos burocráticos e 
autoritários e ao isolacionamento fundamentalista, com a conseqüente perda das vantagens proporcionadas pela tecnologia e pelas formas de organização mais flexíveis que apelam mais à motivação do que à compulsão, mais à participação do que à obediência cega a normas e instruções.

Finalmente, a longo prazo, a globalização tende a proporcionar condições favoráveis ao desenvolvimento sustentável e à democratização política, permitindo também o equacionamento e a solução racionais de problemas que transbordam as fronteiras geográficas dos países, tais como a despoluição dos mares, o controle e o tratamento dos resíduos nucleares, a expansão das redes de comunicação e a aproximação e cooperação entre inúmeros movimentos sociais não-governamentais, recuperando assim, o rumo e o sentido da História.

\section{Das origens}

Contrariamente às interpretações convencionais, os agentes mais dinâmicos da globalização não são os governos nem os representantes parlamentares dos países que formaram mercados comuns à procura de integração econômica. As forças mais ativas e poderosas no processo de globalização são os conglomerados e empresas transnacionais que dominam e controlam efetivamente a maior parte da produção, do comércio, da tecnologia e das finanças internacionais. Com seu imenso potencial econômico-financeiro, essas organizações operam em escalas transcontinentais, transferindo recursos financeiros e know-how por sistemas de comunicações informatizadas e via satélite e crescem, mesmo em tempos de recessão e crise, através de fusões, incorporações, venda e compra de ativos em transações bilionárias. Baseadas em uma cultura organizacional e administrativa sem precedentes na história e dispondo de ativos financeiros superiores aos da maioria dos bancos centrais, a extrema mobilidade de seu capital financeiro movimentado em tempo real por redes computadorizadas integradas, permite realizar altas taxas de lucratividade, inclusive em operações especulativas de câmbio, taxas de juros e preços de commodities, tudo contribuindo para o aumento e a expansão das riquezas e do poder dessas organizações.

A atuação de conglomerados e empresas transnacionais não se limita às esferas econômico-financeiras apenas. Suas decisões de investir e desinvestir afetam, em última análise, a prosperidade ou decadência de cidades e regiões, e o peso de seus recursos econômico-financeiros influi na composição e no funcionamento da estrutura e das instituições políticas. São inúmeros os casos de eleição de representantes do povo cujas campanhas são financiadas pelo grande capital, sem falar dos lobbies e das práticas de corrupção da administração pública, comuns até nas mais altas instâncias dos três poderes.

Essa assimetria de controle e movimentação de recursos humanos, materiais e financeiros expõe cruamente a ilusão de viver-se em uma sociedade democrática. 
Na realidade, verificamos a polarização, a exclusão e os decorrentes desequilíbrios sociais entre minorias desfrutando de elevada renda, consumo e estilo de vida afluentes e de desperdício, face à maioria carente das necessidades básicas. A tendência perversa de extensão da pobreza e de privações é agravada pela incapacidade fiscal-financeira do Estado para atender às demandas e expectativas dos desprivilegiados, enquanto cede às pressões de grupos de interesse corporativistas clamando por privatização das empresas estatais lucrativas, desregulação de preços e tarifas e a abertura total ao livre comércio, sem a mínima preocupação com seus efeitos sociais.

É possível responsabilizar a grande organização pelas disfunções e calamidades que afligem as sociedades contemporâneas? Antes de tentarmos esboçar um prognóstico, convém tecer algumas considerações sobre sua origem e evolução, e a dinâmica que impulsiona o processo de concentração e centralização do capital, potencializado pelo advento das tecnologias de ponta.

Os problemas com as grandes empresas começaram no fim do século passado nos EUA, tendo as manobras de monopolização da Standard Oil of New Jersey provocado a pronta resposta do poder público, sob a forma do Sherman Act (lei antitrust), visando a coibir a prática de preços abusivos por parte dos monopólios. Entretanto, o poder e a influência das grandes empresas não pararam de se expandir, exercendo seu domínio nas comunidades de localização das plantas e, sobretudo, na imposição de condições de trabalho desumanas para os trabalhadores da indústria em geral.

Foi somente com o advento do New Deal de Roosevelt e os contratos coletivos conquistados pelos sindicatos nos anos trinta que o poder das grandes organizações pareceram ter encontrado seus limites. Contornando as restrições impostas pela lei e procurando formas mais adequadas de capitalização capazes de diminuir os ressentimentos da opinião pública e dos consumidores, surgiu em meados deste século a democratização do capital, que transformaria todos em acionistas/proprietários e, destarte, declarou-se a obsolescência da luta de classes. Na prática, a dispersão do capital entre centenas de milhares e milhões de pequenos acionistas facilitou o controle exercido por blocos relativamente pequenos de proprietários e/ou executivos profissionais, estes saudados como a nova elite, mais racional e humana que os tubarões da época heróica de acumulação primitiva.

Possibilitando a dispersão do capital e o controle de conglomerados gigantescos via holdings, sua expansão não parou mais, chegando ao ponto, neste final de século e milênio, em que alguns milhares de grandes organizações controlam mais da metade da produção e do comércio mundiais, enquanto seus grupos financeiros movimentam diariamente centenas de bilhões de dólares aplicações em moedas, ações, commodities ou derivativos, capazes de abalar profundamente os mercados nacionais em várias partes do globo. 


\section{Quem controlará o processo?}

Fazendo parte da nossa estrutura e de nosso estilo de vida e sendo impossível uma volta ao passado, seria possível controlar a grande organização e, eventualmente, responsabilizar seus dirigentes pelos desastres e atrocidades cometidos em nome da liberdade de mercado? À luz das evidências acumuladas, terá sido mera coincidência o uso de termos pouco edificantes, por parte de dois ex-ministros da Fazenda, para qualificar os empresários e seu comportamento ético, na conjuntura atual?

Porta-vozes do grande capital, inclusive alguns vestindo o manto da ciência, afirmam que a função da empresa seria apenas produzir lucro a ser distribuído aos acionistas, aos quais caberia a decisão sobre o que fazer com o excedente. Caberia ao governo o estabelecimento de normas morais, nos limites das quais atuaria a empresa, produzindo para atender à demanda do mercado, seja ela de agrotóxicos, cigarros, medicamentos não suficientemente testados, alimentos contendo substâncias nocivas ou armas letais. Obviamente, o pequeno acionistaproprietário de um certificado de ações é totalmente destituído de poder para influenciar a condução dos negócios e, quanto às leis e normas morais, é patente que essas não são elaboradas de modo independente dos interesses e pressões de diversos grupos e entidades representantes de empresas industriais, agrícolas, bancos, empreiteiras, de turismo, mineração etc. Quanto aos executivos profissionais, supostamente imbuídos de maior responsabilidade social, é constrangedor apontar para inúmeros casos de não recolhimento das contribuições sociais, de sonegação de impostos, de super e subfaturamento na importação e na exportação, recusando-se, via de regra, a considerar os efeitos sociais dessa sua conduta e indiferentes aos problemas humanos - individuais e coletivos - causados por determinadas práticas de negócios. As elites empresariais, proprietários ou executivos de empresas privadas ou estatais, nacionais ou estrangeiras, parecem insensíveis ao drama ao seu redor e, em sua recusa de assumir suas responsabilidades sociais, parecem confirmar o diagnóstico de Hannah Arendt sobre "a banalização do mal”.

O que fazer com as grandes organizações? Seria possível aboli-las ou fechá-las, voltando-se à produção em pequena escala? A tecnologia e o estilo de vida em sociedades complexas exigem a coordenação de imensas quantidades de recursos materiais, financeiros, de equipamentos e máquinas e de trabalhadores, seja na construção de centrais hidrelétricas, na indústria automobilística ou em redes de transporte ferro-rodo-aeroviárias. Mesmo nos países socialistas, os dirigentes das grandes empresas estatais semi-autônomas detinham enorme poder econômicofinanceiro, e sobretudo político, manifesto por pressões e ameaças aos eventuais opositores ou pela cooptação de burocratas e representantes do povo ao aparato. Resistir ou contestar os (des)mandos da tecnoburocracia leva à pecha de inimigo da livre empresa, expressão equivalente hoje ao que fora a acusação de inimigo do Estado no regime do coletivismo burocrático. A ofensiva desenfreada e endossada 
pelos partidos liberais e governos em favor do mercado, da competitividade e da livve empresa confunde até as pessoas razoavelmente informadas e conscientes das calamidades e dos desafios da situação social, sem mencionar os impactos sentidos a longo prazo, através do desemprego e da alienação daqueles que têm a sorte de manter seu posto de trabalho.

Como todos os fenômenos da evolução social, também a globalização insere aspectos positivos e negativos, dando origem a tensões e conflitos entre o antigo e o novo, as tradições e a modernidade, refletidos nas posturas e discursos ideológicos dos diferentes atores sociais.

Constituindo as grandes organizações os motores dinâmicos do processo de globalização, seria possível orientar e controlar seus planos e diretrizes de expansão e acumulação, com poder e visão suficientes para alcançar esses objetivos? Mas, se a resposta for negativa, tendo em vista o discurso neoliberal (e é este o cenário mais provável a médio prazo), quais as propostas para tornar empresas e organizações mais conscientes dos efeitos e responsabilidades pelas conseqüências de determinadas decisões e seus impactos ambientais, sociais e políticos?

O sonho de se conseguir desmembrar as grandes organizações criando muitas pequenas companhias (small is beautiful), além de inviabilizar inúmeros produtos e serviços baseados em tecnologias de grande escala, certamente encontrará enorme resistência e obstáculos políticos, internos e externos. Por outro lado, nada garante que a fragmentação levará as pequenas e médias empresas a zelarem melhor do meio ambiente e a oferecerem condições de trabalho e remuneração mais condizentes aos seus empregados.

A nacionalização das grandes empresas no pós-guerra (França, Reino Unido, Itália etc.), invertida, em parte, pelas políticas econômicas praticadas na década dos oitenta, não tem alterado o quadro em seus aspectos fundamentais, ou seja, a poluição do ar, dos rios e dos mares pelas indústrias de mineração, papel e celulose, siderúrgicas, químicas e petroquímicas embora tenha comprovado a eficiência e competitividade de empresas estatais, cuja dinâmica de expansão, quando bem administrada, não difere da das firmas privadas. Os administradores e tecnocratas das empresas estatizadas tratam seus funcionários à imagem das práticas adotadas nas organizações privadas, enquanto procuram fazer carreira funcional ou política, com idéias confusas sobre o desenvolvimento econômico e as relações políticas entre os diversos segmentos da sociedade.

A ambivalência freqüente entre a qualidade do serviço prestado ao público e a busca de maximização do lucro permeia atitudes, comportamentos e valores dos dirigentes das grandes organizações estatizadas que, via de regra, acabam sendo cooptados e assimilados pela estrutura de poder, seja ela civil ou militar, identificada com a manutenção do status quo. 
A partir dos anos setenta, e na América Latina nos oitenta, os movimentos populares em defesa do meio ambiente e dos consumidores têm se constituído como força política que pareceria capaz de conter o avanço das grandes organizações ou, pelo menos obrigá-las a submeter-se a normas e leis que garantissem segurança e proteção aos vizinhos de usinas nucleares, indústrias petroquímicas, siderúrgicas etc., além de maior transparência em suas operações. As expectativas de mudanças por meio da legislação não foram confirmadas. Por outro lado, os apelos aos investidores institucionais (fundações, igrejas, universidades, pessoas físicas), que supostamente seriam mais sensíveis aos aspectos e problemas éticos e sociais (para exercerem pressão sobre as elites dirigentes), também não têm resultado em mudanças de comportamento significativas.

Permanece o dilema. Não podemos nos livrar das grandes organizações; não sabemos como organizar a sociedade sem elas e continuar, ao mesmo tempo, a prover às necessidades de toda a população. Se, por um lado, é impossível retornar ao passado para viver em pequenas comunidades baseadas em cooperação e solidariedade, por outro, a irracionalidade do sistema de competição selvagem aniquila os indivíduos e o convívio social.

Entre o paroquialismo local primitivo e a acumulação poderosa em escala global, não existiriam outros valores capazes de mobilizar e motivar os membros da sociedade - elites e massas - para humanizar as condições de existência para todos e, assim, restaurar a dignidade e o sentido da vida, na superação do antagonismo entre cooperação e competição; entre o nacionalismo e capitalismo, instituições que garantem e ameaçam ao mesmo tempo, a sobrevivência da espécie humana? Nas sociedades contemporâneas, votos e preços constituem condições necessárias mas não suficientes para um convívio democrático sustentável, quando acompanhadas por desregulação e competição extremas que deixam o poder público impotente diante dos lances e investidas de poderosos interesses privados e corporativos. Em outras palavras, seremos capazes de construir formas de organização e de relacionamento sociais que comportem, ao mesmo tempo, um mínimo de planejamento, orientação e coordenação com o máximo de espaço para a criatividade de indivíduos, solidários e responsáveis?

Referências bibliográficas

AMIN, S. El futuro de la polarización global. Caracas, Nueva Sociedad, n. 132, jul.ago. 1994.

BROWN, S. International relations in a changing global system. Oxford, Westview Press, 1992.

CANTWELL, J. Technological innovation and multinational corporations. Oxford, Blackwell, 1989. 
HOBSBAWM, E. Nações e nacionalismo. Rio de Janeiro, Paz e Terra, 1991.

KEHOANE, R. \& NYE, J. Power and interdependence: world politics in transition. London, Scoth Foreman and Co., 1989.

RATTNER, H. Comércio e desenvolvimento nas sociedades contemporâneas. Revista Politécnica, n. 212/213, p. 66-73, 1994.

REICH, R.B. Who is US? Harvard Business Review, p. 53-64. jan./fev. 1990.

UNITED NATIONS. Transnational corporations in world development. New York, 1989.

Transnational integration, national markets and Nation-States [working paper]. Philadelphia, Reginald Jones Center, The Wharton School, 1991.

WOOD, S. et al. The transformation of work. London, Union Hyman, 1988.

Resumo

O processo de globalização, embora conduzido pela economia, deve ser apreendido, também, em suas dimensões políticas, histórico-culturais e espaciais-ecológicas. Contrariamente à visão idealizada de uma progressão linear de mercados regionais integrados para uma sociedade una e global, a realidade apresenta uma fragmentação do espaço político com novas barreiras e mercados protegidos. Dentre este cenário de tendências contraditórias, o trabalho procura analisar o papel dos principais atores - a ascensão de poderosas organizações que operam em escala transnacional e o Estado-nação cujo poder e influência estão definhando.

Abstract

The process of globalization, although impelled by economic factors, has to be analyzed also in its political, historical and spatial dimensions. Contrarely to the idealized vision of a linear progress from regionally integrated markets toward a unique and global society, reality evidences an increasingly fragmented political space, with new barriers and protected markets. Within this scenario of contradictory trends, the essay endeavors to analyse the role of the main actors - the rise of powerful organizations operating on transnational scale and the declining power and influence of the nation-state.

Henrique Rattner é professor titular aposentado da Faculdade de Economia, Administração e Contabilidade da USP e da EAESP-FGV. É professor emérito da ECEME - Escola de Comando e Estado Maior do Exército e diretor nacional do programa LEAD (Liderança para o Meio Ambiente e Desenvolvimento Sustentável).

Palestra feita pelo autor no IEA-USP em 7 de novembro de 1995. 